\title{
A relação congruente de educação filosófica, autonomia e tecnologias ${ }^{9}$
}

\author{
Luciana Souza de Oliveira Costa \\ Luciana Nunes Garcia Ferreira \\ Priscila Schneider Luciana Nunes Garcia Ferreira ${ }^{10}$
}

Resumo: O presente artigo tem por objetivo refletir acerca das perspectivas educacionais pautadas na educação filosófica, contemplando aspectos do desenvolvimento do conceito de tecnologia oriundo da techné com vistas à autonomia. Para tanto, foi necessário imergir em fontes que se constituíssem como subsídios para a compreensão do que vem a ser a educação filosófica, remontando a pensadores clássicos, como os gregos Platão (A República) e Aristóteles (Metafísica; Ética a Nicômaco); filósofos modernos como Kant (Sobre a Pedagogia) (2004), Rousseau (Emílio ou da Educação) (2004) apoiados nos dicionários de Filosofia de Mora (1978) e de Abbagnano (2007). Uma educação fundamentada contribui para o aprimoramento de uma sociedade e ambas se transformam mutuamente, como reafirmam os autores Chatelet (Uma história da razão) (1994), Jaeger (Paideia, 1995) e Santos (Ágora Digital, 2013). A descoberta dos fundamentos que nos levaram a compreender que a formação do sujeito, enquanto atividade educativa, já presentes nos primórdios da filosofia, indica alguma vinculação entre autonomia e inovações tecnológicas. Pode-se considerar que as tecnologias digitais são hoje, resultado de séculos de desenvolvimento e inovações filosóficas, e que junto às transformações do humano, devem ser contempladas em ambientes de construção de conhecimento.

Palavras-chave: Educação filosófica; Autonomia; Tecnologia.

Submetido em: junho de 2017. Aprovado em: dezembro de 2017

\section{Introdução}

Embora sejamos de distintas áreas de conhecimento, estamos, todas, diretamente vinculadas à educação: uma psicóloga, professora de graduação, uma professora de Educação Infantil e uma professora de Línguas (Português e Inglês) com atuação na Educação Básica. O que nos proporcionou a ideia para a parceria neste artigo e nos uniu num mesmo foco de estudo foram nossos encontros no grupo de estudo NESEF (Núcleo

\footnotetext{
${ }^{9}$ Artigo resultante de trabalho apresentado no XVII encontro do NESEF. Curitiba, UFPR, 22 e 23 de junho de 2017.

${ }^{10}(1)$ LUCIANA SOUZA DE OLIVEIRA COSTA. Mestranda em Educação - Uniplac. $E$ mail: lucianaoliveira@uniplaclages.edu.br; (2) LUCIANA NUNES GARCIA FERREIRA. Mestranda em Educação Uniplac.E mail: lununes@uniplaclages.edu.br ; (3) PRISCILA SCHNEIDER. Professora Mestra - Uniplac. E mail: priscila@uniplaclages.edu.br.
} 
de Estudos e Pesquisa Sobre o Ensino de Filosofia) na UNIPLAC, mediado pela professora Dra. Vanice dos Santos.

Nossa problemática inicial formulou-se quando passamos, através das discussões e estudos filosóficos, a perceber que a filosofia está muito mais presente em nossas vidas pessoais e, principalmente profissionais, do que supúnhamos, embora precisemos reconhecer que ainda nos falta conhecimento, na referida área, que possa ser considerado adequado às necessidades de nossas profissões. Consequentemente, não havíamos explorado seus recursos de grande valia a fim de contribuírem em nossas práticas com vistas à reflexão e compreensão de inúmeros processos educacionais. Assim, algumas relações começaram a fazer sentido, nos instigando a aprofundar nossa pesquisa acerca de três concepções e suas trajetórias históricas: a educação filosófica, a autonomia e a tecnologia.

A Grécia é o berço da Filosofia, de lá surgem instituições políticas, estruturas físicas, relações sociais, entre tantos outros legados dessa civilização clássica, além é claro, de importantes concepções de educação do homem, que têm contribuído, ainda na atualidade, para fundamentar os processos educacionais que vigoram em nosso meio social, bem como os princípios filosóficos que visavam a busca do próprio discernimento, do raciocínio de forma autônoma. Surgem da contribuição grega, também, as primeiras definições de techné (técnica) que, num processo histórico, tanto do termo quanto de sua transformação, possibilitam a significação e a regência da revolução tecnológica no presente.

Desde as profícuas contribuições dos filósofos gregos, muitos outros se juntaram aos seus pensamentos ao longo de séculos, edificando suas ideias e agregando novos valores, mesmo que por uma árdua e sacrificante trajetória de intrigar a sociedade por meio de reflexões críticas, nem sempre bem aceitas.

Em nosso entendimento, a Filosofia, em todos os tempos, tem o papel de questionar-nos, aguçando-nos a observar, analisar, ponderar, num processo de não aceitação do aparentemente óbvio e de reflexão que possibilite considerar acerca de escolhas críticas que levem a um posicionamento, tanto favorável quanto negativo, consciente da postura adotada.

Nesse sentido, a educação filosófica contribui significativamente no processo de formação do sujeito que, desde o período grego, supõe-se ser preparado para as relações sociais e sua contribuição enquanto cidadão da polis. 
A origem etimológica da palavra autonomia remonta do grego autos, que significa "a si próprio", e nomos, que significa "lei" (SACCONI, 2010), portanto, remete a propriedade de autolegislar ou autogovernar. Contudo, foi Emmanuel Kant que primeiramente a empregou, conforme Abbagnano explica, "para designar a independência da vontade em relação a qualquer desejo ou objeto de desejo e a sua capacidade de determinar-se em conformidade com uma lei própria, que é a da razão.” (2007, p.98). Percebemos que, embora relativamente novo este termo, há muito vem se discutindo a capacidade das pessoas em estarem no comando de suas próprias ações, com o controle de suas faculdades, a partir de um processo reflexivo que torne possível esta emancipação autônoma.

Tendo posto tais explicações, nosso objetivo, e grande desafio, neste artigo, se firma na busca de compreender as relações intrínsecas entre as três palavras chaves para possibilitar a reflexão acerca das perspectivas educacionais pautadas na educação filosófica, e contemplar aspectos do desenvolvimento do conceito de tecnologia oriundo da techné com vistas à autonomia.

\section{Contribuições da Educação Filosófica para a autonomia}

A educação é propriedade de toda a sociedade, e cada comunidade reflete seu próprio conhecimento. O desenvolvimento do sujeito, com vistas à educação, tem vínculo indissociável com a Filosofia, pois ela tem a função de aguçar os sentidos de reflexão, o questionamento, o raciocínio, a criticidade e a consciência do educando, promover a formação de virtudes e, destarte, prepará-lo para o exercício de sua cidadania. A Grécia representa a origem da vida social de princípios, cultura e educação. Sua contribuição para o desenvolvimento cultural da humanidade não tem precedentes. Estas assertivas encontram respaldo no pensamento de Jaeger (1994), ao reconhecer que a Paidéia possibilita um embasamento para o conhecimento e para a educação vigente. Para ele, esta é uma das heranças dos pensadores gregos, pois somente o homem pode perpassar o seu conhecimento através do tempo, uma vez que sente-se impelido a transmitir sua sapiência. Assim, a educação é consequência de uma regra viva que rege a sociedade, ela transforma o indivíduo e, portanto por meio da impressão de valores no meio social, educação e comunidade co-evoluem. Para compreendermos a concepção filosófica a respeito de educação, Abbagnano (2007) traz a seguinte definição: 


\begin{abstract}
"Em geral, designa-se com esse termo a transmissão e o aprendizado das técnicas culturais, que são as técnicas de uso, produção e comportamento, mediante as quais um grupo de homens é capaz de satisfazer suas necessidades, proteger-se contra a hostilidade do ambiente físico e biológico e trabalhar em conjunto, de modo mais ou menos ordenado e pacífico. [...] as modalidades ou formas de realizar ou garantir essa transmissão chamam-se educação." (ABBAGNANO, 2007, p.305, 306).
\end{abstract}

Platão (1991), quando retomou o pensamento de Sócrates, salientou que a educação é o ponto mais sólido na construção do caráter do indivíduo. Desta forma, as virtudes são decorrências da instrução e, por meio delas, busca-se a ação do bem, a brandura e a integridade. Segundo ele, o ensino deve ter início na infância e seguir por toda a juventude do homem. Portanto, se os jovens forem educados adequadamente, com esclarecimento, serão capazes de compreender as justiças e injustiças sociais uma vez que, quando sólida, a educação torna melhor os que a precederam, aprimora o caráter do educando, lhes resguarda a retidão e legitimidade de opinião, e lhes incute o respeito ao próximo e às leis.

Teixeira e Horn (2017), estudando a educação na visão de Sócrates consideraram que, para este filósofo, a educação acontece por meio do diálogo, portanto, ambos, professor e aluno, encontram a verdade dos fatos por meio da maiêutica. Dessa forma, cabe ao professor oportunizar meios para que, através do uso da razão, o educando construa seu próprio discernimento.

A educação tem como alicerce um objetivo prioritário: deve ser a formação do equilíbrio, da evolução sadia dos sentimentos, destacando o desenvolvimento da personalidade individual do aluno. Educar pressupõe método, direção e orientação. (Teixeira e Horn, 2017, p. 38).

Direcionando nosso olhar para a temática deste artigo, percebemos que a relação da educação filosófica e da autonomia já eram abordadas por Jean Jacques Rousseau, pois em seu livro "Emílio ou da Educação" ressaltava as questões relacionadas à "emancipação humana, da autonomia do sujeito, da educação pelo método de ensino natural, pela capacidade de refletir e agir filosoficamente" (TEIXEIRA E HORN, 2017, p.23). Sua intenção sempre foi enfatizar que as pessoas têm capacidade, faculdade de estarem no controle de seus próprios poderes, em qualquer contexto.

Rousseau tratava do papel da Educação na sociedade enquanto humanizadora, afirmava que a Educação é uma arte e que concerne à mãe e ao pai desse indivíduo realizá-la de forma natural, sem negligências, sem vícios e caprichos, até que este se tornasse adulto. Desta forma, a educação deveria ser oriunda da natureza, proveniente 
dos homens e das coisas e deveria-se tentar aproximá-la ao máximo do sucesso, mesmo que não houvesse garantias de êxito ao conseguir abranger esses três pontos em uma educação. Nesta perspectiva, o homem deveria ser educado primeiramente para sua natureza humana, só depois para seguir um caminho profissional, considerando que o sujeito educado para o mundo sabe se defender dos percalços da vida. Dizia o autor que a educação era o que formava o homem, ele nada seria se fosse apenas grande e forte.

O único hábito que se deve deixar a criança adquirir é de não contrair
nenhum; [...] Preparai de longe o reinado de sua liberdade e o emprego de
suas forças, deixando a seu corpo o hábito natural, pondo-a em estado de ser
sempre senhora de si mesma e fazendo em tudo sua vontade logo que tenha
uma (ROUSSEAU, 1995, p. 43).

O êxito na arte de educar seria quase impossível, haja vista que quem educa não tem controle sobre o processo de educação como um todo. A sensibilidade do ser humano seria inata, os objetos que o cercam é que influenciariam sua mudança.

O pai de Emílio enfatizou também o aprisionamento que escravizaria o homem em todas as fases de sua vida, seja por cueiros, por instituições ou por um caixão, sem nunca haver escolha de movimento e prejudicando o desenvolvimento de seus membros amarrados. Destarte, a criança não deveria acostumar-se com nada, tudo deveria ser modificado antes que ela tomasse por hábito. Nesta direção, Rousseau (1995), acreditava que, desde muito cedo, o choro da criança deveria ser ignorado, sem que lhe fossem omitidos cuidados, para que ela compreendesse que suas vontades não seriam atendidas por meio deste subterfúgio, e na medida em que fosse possível, ela mesma poderia alcançar seus objetivos e ir tornando-se cada vez mais autônoma. A partir dessa perspectiva podemos considerar que a autonomia é construída pela ação educativa, à medida que a criança é confrontada com suas responsabilidades.

Sabendo das fraquezas do ser humano, Rousseau (1995) falava sobre os cuidados com as crianças para que não fugíssemos do caminho da natureza, definindo quatro máximas: 1. Dar-lhes forças para as necessidades da natureza; 2. Suprir o que carecem, seja em inteligência, em força ou às necessidades físicas; 3. Restringir o auxílio apenas no que fosse útil real. Estas regras as deixariam mais livres e menos voluntariosas.

Rousseau (1995), afirma que a educação prática desenvolve a habilidade, a prudência e a moral. Por meio de uma habilidade sólida é possível traduzir emoções, construir o hábito de pensar e encontrar o talento; a prudência é a arte do decoro, na 
ponderação de conduta; a moralidade, é a construção do caráter, pelo domínio das paixões, e a honra da palavra.

Teixeira e Horn (2017), ao analisar os estudos de Rousseau em relação à educação e à autonomia, observaram que, a educação filosófica que visa o desenvolvimento da autonomia é a que ensina o sujeito a pensar por si, através de uma educação natural e emancipatória. O processo de reflexão e ação pautada na consciência dos próprios poderes, expressa plenamente a obtenção da independência de pensamento e ação. Desta forma, é necessário que o processo educacional seja integral, de modo que permita ao sujeito pensar por si mesmo. A educação que visa a liberdade guiada pela ética, consequentemente atinge a autonomia. Para tanto, o caráter do educando deve ser observado, governado e disciplinado, para que só então ele possa usufruir de sua auto suficiência. Assim, a educação prática da liberdade estará embasada no senso crítico, na moralidade e na consciência da posse de direitos e deveres.

Segundo estes estudiosos, a educação de Rousseau, é aquela que leva o sujeito a perceber as próprias adversidades, e pensando por si mesmo encontrar as soluções. Esse processo poderá ser construído por meio da troca de experiências e de conhecimentos, tornando o indivíduo auto suficiente com o passar do tempo.

Ao analisar obras de Kant, Teixeira e Horn (2017) observaram que, para este pensador, a educação filosófica é aquela que ensina o aluno a pensar por si mesmo, levando-o a usar a razão de forma autônoma. Aborda-se aqui o preceito Aufklärung, que tem por princípio o aprendizado do filosofar, em que o exercício das capacidades cognitivas, levam a autonomia da razão, pontuados nos princípios filosóficos refletir, criticar e analisar.

O filósofo Kant (1999), definiu educação através de uma tríade: cuidado na infância, disciplina e instrução com formação. Assim, ao refletir sobre a pedagogia, afirmou que o ser humano é o único animal que precisa ser educado, os demais necessitam apenas serem alimentados, protegidos e conduzidos. O homem requer cuidados especiais para que, tempos depois, siga por si seu caminho. A partir desta consideração, ele apontou que a disciplina é necessária ao homem para inibir sua selvageria, pois este deve estar subordinado à razão e suas condutas necessitam mostrar suas qualidades humanas. A disciplina, para ele, tem importância primeira na educação, pois ela estabelecerá uma espécie de rotina de treinamento onde o homem começa a ser moldado em relação à sua conduta. "A disciplina transforma a animalidade em humanidade" (p.12). Nesse contexto, a educação é moldada através das gerações, num 
processo progressivo que prescreve a arte de educar. Desta forma, o sujeito precisa estar submetido à disciplina e à instrução o mais cedo possível, porque quanto mais tarde, mais difícil será restringir sua animalidade.

Mais importante do que ter cultura é ter disciplina, pois para o autor, "[...] quem não tem cultura de nenhuma espécie é um bruto; quem não tem disciplina é um selvagem" (p.16). Portanto, a cultura pode ser adquirida mais tarde, diferentemente da disciplina. O homem deixa a selvageria quando é disciplinado à submissão das leis, desde cedo para que não adquiram vícios que o atrapalhem nesse processo disciplinar de formação da razão. É possível perceber na fala de Kant sua busca pelo equilíbrio nesse processo, a fim de que nem haja controle ou zelo excessivo, nem falta de oposição resistência. Além da disciplina, Kant considera que a instrução também é uma formação necessária exclusivamente do ser humano, com exceção dos pássaros que aprendem a cantar com seus ascendentes. $\mathrm{O}$ homem se torna verdadeiro pela educação, sendo a disciplina e a instrução requisitos necessários para que os mestres formem seus educandos. Assim, a educação é passada de geração em geração, pelas quais os conhecimentos adquiridos vão sendo aperfeiçoados continuamente, uma vez que cada geração otimiza o conhecimento adquirido e os transmite de forma melhorada. Dessa maneira, o objetivo da educação é desenvolver as disposições humanas naturais de modo a atingir a destinação do homem, a humanidade em sua perfeição.

No entanto, para este filósofo, a natureza humana não alcançou o segredo da perfeição por ainda precisar ser aprimorada pela educação, que assim se torna um problema por ser uma teoria idealizada na busca da felicidade da espécie humana. Mas, segundo ele, não há obstáculos impossíveis de serem sobrepujados, basta buscar a superação através da experiência de uma educação voltada para o futuro. Tal finalidade, diferente dos animais, deve ser buscada pela espécie humana como um todo. Pois, para Kant, o processo de educação deve durar até que o homem seja capaz de guiar-se com autonomia, passando a educar ao invés de ser educado.

Ainda segundo Kant (1999), é necessário solidar o caráter na infância, por meio de exemplos, regras e deveres a cumprir. Instruir para com os deveres consigo mesma e também quanto aos deveres para com os demais, a consciência sobre os direitos dos outros, o respeito ao próximo e a humildade. Segundo o filósofo, o sujeito é educado até que possa educar, quando tenha sua liberdade submetida às normas e ao bem comum. As regras são a base para a liberdade com segurança, a partir do princípio de que o poder de um não deve interferir no direito do outro. 
De acordo esse pensador, a educação pode ser física, quando se refere aos cuidados com o corpo; ou prática, que trata da moral, da educação para a liberdade e para viver em sociedade. Ela, ainda compõe-se em formação escolástica, que são as habilidades dos indivíduos; formação pragmática, que aborda a prudência, a formação do cidadão e sua interação na sociedade; formação moral, que trata da moralidade e da consciência de princípios e valores para com a espécie humana. A educação física explana sobre as atenções materiais, cuidados com o corpo, pois a educação precisa fortalecer o indivíduo e, a sua independência depende, dele não estar preso à inclinações ou hábitos. Costumes podam a liberdade. Desta forma, a boa educação é a fonte do bem, em oposição à educação que não submete a natureza humana às regras, que é uma má educação. Portanto, ainda que o sujeito tenha disposição para o bem, é necessário que seja educado de forma a desenvolver a moralidade.

Tomando por base várias argumentações aqui abordadas, podemos constatar que, a educação filosófica é aquela que promove a construção do conhecimento, de forma que o aluno possa pensar e agir de acordo com seus próprios conhecimentos, de forma livre e autônoma. A filosofia da educação está respaldada no aperfeiçoamento contínuo, no qual cada indivíduo deve aprimorar seus conhecimentos possibilitando seu crescimento como ser humano. Desta forma o desenvolvimento do ser humano, por toda sua existência está pautado nas transformações culturais, científicas e tecnológicas.

Ao longo da história da humanidade, desde os remotos tempos da Grécia Antiga, os conhecimentos e experiências foram sendo registrados e repassados através de inúmeras gerações, num processo de reconstrução e aprimoramento a partir do que já existia, numa constante renovação de conceitos e resultados, possibilitados pelos registros de memória de todos os antecessores aos seus tempos. Reconhece-se nesta trajetória, a relevante atribuição da educação filosófica e do desenvolvimento da autonomia, mesmo quando ainda não bem definidas e compreendidas, para assegurar tal movimento. Evidências acerca da assertiva inicial deste parágrafo podem ser encontradas em descrições de Aristóteles (1984), ao referir-se sobre a experiência, a arte e o raciocínio:

Mas a espécie humana [vive] também de arte e de raciocínios. É da memória que deriva aos homens a experiência: pois as recordações repetidas da mesma coisa produzem o efeito duma única experiência, e a experiência quase se parece com a ciência e a arte. Na realidade, porém, a ciência e a arte vêm aos homens por intermédio da experiência, porque a experiência, como afirma 
Polos, e bem, criou a arte, e a inexperiência, o acaso. E a arte aparece quando, de um complexo de noções experimentadas, se exprime um único juízo universal dos [casos] semelhantes. Com efeito, ter a noção de que a Cálias, atingido de tal doença, tal remédio deu alívio, e a Sócrates também, e, da mesma maneira, a outros tomados singularmente, é da experiência; mas julgar que tenha aliviado a todos os semelhantes, determinados segundo uma única espécie, atingidos de tal doença, como os fleumáticos, os biliosos, ou os incomodados por febre ardente, isso é da arte. Ora, no que respeita à vida prática, a experiência em nada parece diferir da arte; [...] E isso porque a experiência é conhecimento dos singulares, e a arte, dos universais; [...] (ARISTÓTELES, 1984b, p. 11)

Embora não fosse possível descrever detalhadamente onde se chegaria por meio desta trajetória, os filósofos da época demonstravam, como apontam os registros, uma expansão de experiências da arte ou técnica que serviriam ao sujeito como forma de apropriação de novas tecnologias, sempre visando o seu benefício (mesmo que aparente, em alguns casos).

\section{As tecnologias: da origem dos termos e usos às suas proposições atuais}

Ao buscar compreender as expressões techné, técnica e tecnologia, elas se apresentam em uma linha de soerguimento que se constitui exatamente na concepção de experiência, arte e raciocínio que possibilitaram uma progressão de conhecimentos e conceitos, com descobertas e definições que são incorporados ao longo da trajetória do estudo filosófico. Definida como arte, ou techné, nos primórdios, a técnica, em suas diferentes interpretações, pode ser reconhecida como sendo tão antiga quanto a existência do homem. Esta assertiva pode ser validada a partir dos estudos dos autores que neste texto dialogam e esclarecem. Neste sentido, Jaeger considerou a techne como um dos fatores indispensáveis para o domínio da arte, que vem a contribuir para a demarcação dos abstrusos caminhos e escolhas que a humanidade tende a seguir, devendo encontrar soluções para as situações inesperadas: “[...] a techne, que lhes acrescenta o que a arte do timoneiro faz no meio da tempestade, ajuda por certo nada desprezível” (p. 1339).

Neste mesmo sentido, a definição de tecnologia é encontrada no dicionário de Filosofia de Abbagnano, justamente como equivalente à técnica, mais uma vez comparada com os termos arte e ciência ou, nas palavras do autor, "estudo de processos técnicos de determinado ramo da produção industrial ou de vários ramos" (2007, p. 942). Ainda de acordo com o autor, a técnica pode ser entendida por um apanhado de regras as quais possibilitam executar qualquer atividade humana com eficácia. A arte como técnica pode ser entendida, dentre os autores aqui referenciados, tanto por 
Aristóteles (1984b) como por Jaeger (1994), sendo explicada, ainda por Abbagnano (2007), que divide a técnica entre o campo de procedimentos racionais e o campo das técnicas mágicas e religiosas, diferenciadas por a primeira ser autocorrigível e poder mudar o sistema de crenças, e a segunda por estar limitada em suas práticas. Além disso, de acordo com seu dicionário, Abbagnano (2007) revela a técnica como sendo indispensável à sobrevivência humana.

Ao observar e questionar a relação de diálogo entre tutor e aluno em ambientes virtuais, Santos (2013) reconheceu em seus estudos a possibilidade de reformulação de uma nova Ágora, semelhante à Grega, como espaço de discussão e interação dialógica, pautada no uso de ferramentas tecnológicas, nomeando-a de "Ágora Digital”. Nesta perspectiva, percebemos a evidente fusão dos conceitos e práticas primitivos aos contemporâneos.

A autora enfatiza a importância do cuidado de si, referido por Foucault como primordial ao sujeito que busca estabelecer qualquer relação com outros sujeitos, uma vez que não seria possível preocupar-se e interagir com o outro, cuidar do outro, sem que previamente tenha tal prática de forma reflexiva. Neste sentido, percebemos que o cuidado de si implica o desenvolvimento de práticas autônomas, que vão muito além do que o conhecer a si mesmo, realçado por Sócrates.

\begin{abstract}
Ora, da relação comparativa entre epimeleia heautou e gnothi seauton deriva uma regra lógico-formal na qual somente posso pensar o conhecer a mim mesmo se já cuido de mim mesmo, se já estou previamente abarcado pelo despertar que o cuidado de si produz em mim mesmo. Não posso derivar o cuidado de si, mas posso a partir da clareira aberta pelo conhecer-me a mim mesmo, compreender mais profundamente a estrutura prévia do cuidado de si. Isto não significa que do cuidado de si deriva naturalmente o conhece-te a ti mesmo, mas que a base do conhecimento enquanto tal e a sua essência talvez não estejam totalmente identificadas com ele, assim como a essência do conhecer não se confunde com o próprio conhecer, bem como a essência da técnica é não técnica. (SANTOS, 2013, p. 29)
\end{abstract}

A partir destas concepções, percebemos as relações tecnológicas que emergem vinculadas ao processo de desenvolvimento da educação filosófica e da autonomia do sujeito que necessita conhecer-se a si mesmo com vistas a alcançar um equilíbrio pessoal que os três termos, ao mesmo tempo, demandam e proporcionam.

Daí surgem as preocupações da construção de ambientes virtuais que realmente venham a constituir espaços de diálogos autênticos, que desenvolvam, tanto para o tutor quanto para seu aluno, reflexões oriundas de uma educação filosófica com contribuições pertinentes ao processo de formação dos sujeitos envolvidos. 
Entretanto, somos colocados diante do impasse e paradoxo de vivenciarmos, em nossa prática docente, experiências didático-pedagógicas que são realizadas em ambientes suportados por computadores e, neste aspecto, configurando-se como ambientes virtuais de aprendizagem. Oriundos da filosofia e das práticas tradicionais de ensino, [...] nos deparamos com o desafio de fazermos o pensar filosófico e sua metodologia falarem também no mundo digital. (SANTOS, 2013, p. 59).

Assim, devido ao fato de a tecnologia há muito colaborar com os processos de formação na educação, percebemos a necessidade de que os sujeitos envolvidos exerçam seus papéis com autonomia e, desta forma, reconheçam a sua presença, e alcancem a compreensão sobre as diversas formas como se faz presente, o seu uso, a sua história, o seu sentido tanto pelo educador quanto pelo educando.

\section{Considerações finais}

A Filosofia, e/ou a educação filosófica, tem o papel de pôr-nos a refletir, com bom senso e equilíbrio, acerca dos constantes processos de transformação, desde a techné, até o advento tecnológico, com vistas a conhecer, compreender, bem usufruir e, até mesmo, refutar as inovações que se impõem, sempre diferentes e aprimoradas, ao longo dos tempos.

Tendo em vista os aspectos observados, pode-se constatar que a educação é responsável pela formação e o aperfeiçoamento humano e, portanto, o desenvolvimento de uma sociedade está fundamentado na educação. Desta forma, para alguns pensadores, a educação, desde a Grécia antiga, tem uma abordagem filosófica, uma vez que, por meio dela, mestres e educandos buscam sabedoria, emancipação intelectual e evolução científica. Assim a educação filosófica promove a construção do conhecimento do indivíduo, levando-o a estruturar seus próprios pensamentos de modo a embasar suas ações. Dessa forma com o passar do tempo, todo conhecimento adquirido será o alicerce que sustentará o exercício da autonomia do aluno em sua vida. Portanto, tanto a educação filosófica quanto as tecnologias acompanham o desenvolvimento histórico da humanidade, e contribuem para a construção de pensamentos e de ações com vistas ao crescimento moral, intelectual e científico de um povo e sua autonomia.

Techné, técnica e tecnologia são termos semelhantes que remontam a períodos históricos diferentes quanto ao seu desenvolvimento. Tratam de se complementarem a medida em que surgem as inovações pertinentes aos seus contextos. Esse processo de criação, recriação e transformação tiveram sempre como objetivo a satisfação de necessidades oriundas do sujeito ou da sociedade, pois tudo o que foi projetado, sempre 
atendeu a requisitos da humanidade. Assim, gradativamente, percebemos a incorporação, seguida da influência ou interferência da tecnologia nos mais diversos segmentos como os exemplos: economia, saúde, política, comunicação, transporte, lazer, cultura, esporte, atividades domésticas e, numa menor proporção, na atividade educacional, conquanto saibamos que há uma estreita relação entre as duas e que, muito há o que se explorar das tecnologias atuais para uma vultosa contribuição à educação, com vistas ao desenvolvimento de sujeitos autônomos.

\section{REFERÊNCIAS}

ABBAGNANO, Nicola. Dicionário de Filosofia. 5ed. São Paulo: Martins Fontes, 2007.

ARISTÓTELES. Ética a Nicômaco. Tradução de Leonel Vallandro e Gerd Bornheim. São Paulo: Editora Abril S.A. Cultural, 1984a.

ARISTÓTELES. Metafísica. Tradução de Vincenzo Cocco. São Paulo: Editora Abril S.A. Cultural, 1984b.

CHATELET, François. Uma história da razão: entrevistas com Émile Noël. Rio de Janeiro: Jorge Zahar, 1994.

JAEGER, Werner Wilhelm, 1888-1961. Paidéia: a formação do homem grego. Trad. Artur M. Parreira. $3^{\text {a }}$ Ed. - São Paulo: Martins Fontes, 1994.

JAPIASSÚ, Hilton; MARCONDES, Danilo. Dicionário Básico De Filosofia. $3^{\text {a }}$ edição.Revisão e ampliação de Jorge Zahar Editor. Digitalizado por TupyKurumin. Rio de Janeiro, 2001. Disponível em: http://raycydio.yolasite.com/resources/dicionario_de_filosofia_japiassu.pdf. Acesso em: 17/06/2017.

KANT, Immanuel. Sobre a Pedagogia, Tradução de Francisco Cock Fontanella. $2^{\mathrm{a}}$ ed. Piracicaba. Editora Unimep, 1999.

MORA, José Ferrater. Dicionário de Filosofia. Texto preparado por Eduardo Garc A. Belsunce e Ezequiel Olaso. Traduzido do Espanhol por António José Massano e Manuel Palmeirim. Lisboa: Publicações Dom Quixote: 1978.

PLATÃO. A República. São Paulo: Nova Cultural, 1991. (Coleção Os Pensadores)

ROUSSEAU, Jean Jacques. Emílio ou da Educação. Tradução de Sérgio Milliet. 3.ed. Rio de janeiro: Bertrand Brasil, 1995.

SACCONI, Luiz Antonio. Grande Dicionário Sacconi: da língua portuguesa: comentado, crítico e enciclopédico. São Paulo: Nova Geração, 2010. 
SANTOS, Vanice dos. Ágora digital: o cuidado de si no caminho do diálogo entre tutor e aluno em ambiente virtual de aprendizagem Jundiaí: Paco. 2013.

TEIXEIRA, Luciana da Silva; HORN, Geraldo Balduíno. Didática do Ensino de Filosofia: pressupostos teórico-metodológicos. Curitiba: Editora CRV, 2017. 